\title{
Produtos do Mestrado Profissional: instrumentos de mudanças na formação e nas práticas profissionais na promoção e prevenção do tabagismo
}

\section{Professional Master's Products: change instruments in training and professional practices in the promotion and prevention of smoking}

\author{
Vilma Silva ${ }^{1}$, Ana Clementina Almeida², Lúcia Mourão ${ }^{3}$
}

\author{
${ }^{1}$ Mestra, Universidade Federal Fluminense, Niterói Rio de Janeiro, Brasil - E-mail, vilma.vieira@ globo.com,/ORCID: 0000- \\ 0002-3299-6055 \\ ${ }^{2}$ Doutora, Universidade Federal Fluminense, Niterói Rio de Janeiro, Brasil - E-mail, \\ ana.vieiradealmeida@gmail.com,/ORCID: 0000-0002-9342-6179 \\ ${ }^{3}$ Doutora. Universidade Federal Fluminense, Niterói Rio de Janeiro, Brasil - E-mail, luciamourao@ @otmail.com,/ORCID: \\ 0000-0002-7058-4908
}

\section{Recebido em Junho/2019. Publicado em Agosto/2020}

Palavras-chave:

Promoção da Saúde. Prevenção do Hábito de Fumar. Tabagismo. Pessoal de Saúde da Família. Estudantes.

\section{Keywords:}

Health

Promotion.

Prevention of Moking Habit. Smoking. Family Health Team. Health Undergraduates.
RESUMO: Trata-se de um relato, que parte dos resultados obtidos na dissertação de mestrado profissional em ensino na saúde da Universidade Federal Fluminense que traz como problema o pouco envolvimento de profissionais de saúde e de alunos em formação no controle do tabagismo. Objetiva apresentar e trazer para reflexões a questão do tabagismo e as ações de promoção e prevenção a ele relacionadas, a partir de duas estratégias elaboradas com vistas a favorecer a formação e as práticas dos profissionais de saúde na Estratégia Saúde da família. Utiliza como referencial teórico metodológico a análise institucional, colocando em debates coletivos o problema do tabagismo em intervenção nos moldes da socioclínica institucional. Como resultados dos debates foram evidenciados que crianças e adolescentes eram o grupo mais vulnerável à iniciação ao tabaco e que esta temática era pouco abordada durante a formação dos profissionais de saúde. Foram elaboradas duas estratégias sendo uma delas um formulário para identificar os fumantes de um Módulo Médico de Família, de Niterói/Rio de Janeiro, quantos desejavam parar de fumar, e se tinham crianças e ou adolescentes nas famílias, e outra, um curso de capacitação sobre tabagismo desenvolvido por estudantes de farmácia e aplicado aos agentes comunitários de saúde. Considera que o processo de intervenção contribuiu na elaboração dos produtos a partir das estratégias pensadas nos debates, e favoreceu mudanças na maneira dos participantes entenderem o tabagismo, enfatizando a corresponsabilidade dos serviços e do ensino na promoção e prevenção ao tabagismo.

ABSTRACT: It is a report originated from the results achieved in a professional master course dissertation in Health Education of Federal Fluminense University, which brings with it the problem of little involvement of health professionals and students on training in smoking control. The objective is to present and bring to reflection the issue of smoking and related promotion and prevention actions. Two elaborated strategies are used in order to favor the health professionals training and practices in the Family Health Strategy. The institutional analysis is applied as theoretical and methodological reference, putting in collective debates the smoking problem in intervention meetings in the molds of institutional socioclinical. As a result of the discussions, it was evidenced that children and teenagers were the most vulnerable group to tobacco initiation and that this theme was seldom approached during the training of health professionals. Two strategies were developed, one of them being a form to identify smokers in a Family Medical Module, from Niterói/Rio 
de Janeiro, how many wanted to quit smoking, and if they had children and/or teens in the family, and the other a training course on smoking, developed by pharmacy undergraduates and applied to community health agents. It is considered that the intervention process contributed to the elaboration of products from the strategies devised in debates, and favored changes in the way participants could understand smoking, emphasizing the co-responsibility of services and teaching on the promotion of and prevention of smoking.

\section{INTRODUÇÃO}

Para promover saúde deve-se refletir sobre o objeto do cuidado em saúde, considerando-a um conceito em construção que depende de valores sociais, culturais e históricos, que permitam viver com qualidade. As ações de promoção à saúde propõem reorientar os serviços de saúde, indo à busca de atenção integral às pessoas em suas necessidades, visando alcançar a qualidade de vida em seu sentido mais amplo, e lutando contra as desigualdades por meio da construção de cidadania. Essas ações estão contempladas na Política Nacional de Promoção da Saúde, aprovada pela portaria $n^{\circ}$ 687, de 30 de março de 2006 (BRASIL, 2006).

No caso do controle do tabagismo, o interesse se volta às práticas de promoção e prevenção da doença. A nicotina do tabaco causa dependência química similar à dependência de drogas como heroína e cocaína. O tabagismo está na décima revisão da Classificação Internacional de Doenças (CID-10), no grupo dos transtornos mentais e de comportamento decorrentes do uso de substância psicoativa. É considerada uma doença pediátrica, pois a idade média da iniciação é 15 anos. Comporta-se como uma doença crônica e seu tratamento deve ser valorizado, fazendo parte das rotinas de atendimento de unidades de saúde do Sistema Único de Saúde (BRASIL, 2007).

Apesar das ações governamentais e não governamentais para o controle do tabaco antecederem o ano de 1989, foi a partir da Constituição Federal de 1988 e da criação do Sistema Único de Saúde, em um contexto de crescente reconhecimento e valorização do conceito da Promoção de Saúde, que se iniciou a sua organização efetiva. Há, então, a ampliação marcante da legislação e a definição das responsabilidades de órgãos específicos, culminando no desenho de Políticas Nacionais específicas, por exemplo, a Política Nacional de Promoção da Saúde, revisada em 2014. Nessa perspectiva, um dos marcos estratégicos essenciais para propiciar o alcance nacional dessas ações foi a articulação de uma rede de parcerias, envolvendo representações de Secretarias Estaduais e Municipais de Saúde (que permitiu a descentralização da gerência das ações de controle do tabagismo em estados e municípios), de diferentes setores do Ministério da Saúde, de outros ministérios, assim como de organizações não governamentais e de organizações internacionais intergovernamentais no âmbito regional e global (BRASIL, 2001; ROMERO; COSTA; SILVA, 2011). 
O Programa Nacional de Controle do Tabagismo (PNCT) foi construído, envolvendo dois grupos de ações: o primeiro, voltado para prevenção da iniciação do tabagismo, tendo como público-alvo crianças e adolescentes; o segundo, envolvendo ações para estimular os fumantes a deixarem de fumar. Ambos os enfoques são reforçados por ações legislativas, econômicas e ações de comunicação social (BRASIL, 2007). Apesar disso, dados recentes mostram que dos tabagistas que tentam parar de fumar (aproximadamente metade do total de tabagistas), apenas uma minoria recebe aconselhamento de um profissional de saúde sobre como parar e uma parte menor ainda recebe um acompanhamento adequado para este fim (BRASIL, 2015).

Para enfrentar essa questão, com o intuito de universalizar o tratamento do tabagismo, o Ministério da Saúde reviu a antiga portaria com as diretrizes para o Programa Nacional de Controle do Tabagismo e publicou nova portaria em 2013 (BRASIL, 2013), que define como lócus principal de cuidado, da pessoa que fuma, a Atenção Básica, nível de atenção à saúde mais capilarizado e próximo dos usuários.

O tabagismo é um problema de saúde pública ao responder por 40 a $50 \%$ de todas as mortes por câncer, 75\% das mortes por Doença Pulmonar Obstrutiva Crônica (DPOC), cerca de $20 \%$ das mortes por doenças vasculares, 35\% das mortes por doenças cardiovasculares, entre homens de 35 a 69 anos de idade, nos países desenvolvidos (BRASIL, 2001).

De acordo com a Organização Mundial de Saúde, o tabagismo é responsável por cerca de cinco milhões de mortes por ano em todo o mundo - somente aqui no Brasil são mais de 200 mil mortes. Ele mata mais que AIDS, malária, tuberculose, crack, cocaína e heroína em conjunto, configurando-se como a maior causa evitável de doenças, invalidez e morte (BRASIL, 2007).

Em face desse quadro, a primeira autora como médica da Estratégia Saúde da Família (ESF) percebia a gravidade do problema, pois se de um lado, os dados da literatura revelavam os problemas que a nicotina acarreta na saúde física e mental dos indivíduos, de outro, observava o pouco envolvimento de profissionais de saúde e de alunos em formação em participar de ações de promoção e prevenção contra o tabagismo. Acrescenta-se a este contexto, a pouca adesão dos usuários nas atividades de grupo de controle do tabagismo oferecidas pela unidade de saúde, em consonância com as diretrizes da política de saúde.

Diante dessa problemática formularam-se os seguintes questionamentos que embasaram este relato de experiência: que ações de promoção e prevenção ao tabagismo podem ser desenvolvidas pelos profissionais de saúde e alunos em formação na ESF? De que maneira envolver os usuários nestas ações? 
Ao buscar a resposta a estes e outros questionamentos, realizou-se uma pesquisa junto ao Mestrado Profissional de Ensino na Saúde da Universidade Federal Fluminense, que ampliasse o conhecimento sobre essa problemática, o que resultou na elaboração de dois produtos que serão aqui relatados.

Nesse sentido este relato objetiva apresentar e trazer para reflexões a questão do tabagismo e as ações de promoção e prevenção a ele relacionadas, a partir de duas estratégias elaboradas com vistas a favorecer a formação e as práticas dos profissionais de saúde.

\section{ALGUMAS CONSIDERAÇÕES SOBRE OS PRODUTOS DO MESTRADO PROFISSIONAL}

Os mestrados profissionais brasileiros foram instituídos em 1995, pela Portaria $n^{\circ} 47$, da Coordenação de Aperfeiçoamento de Pessoal de Nível Superior (CAPES), que foi revogada, no entanto, foi regulamenta pela Portaria nº 80/1998, do Ministério da Educação (BRASIL, 1998). Busca efetuar uma mudança qualitativa na formação dos profissionais que já estão inseridos no mundo do trabalho, conservando o mesmo padrão de exigência e de qualidade do mestrado acadêmico (BRASIL, 2009a). Como pré-requisito, tem como ingressantes majoritariamente alunos com experiência profissional, enfatizando a necessidade de parceria com os serviços dos quais os alunos são originados. Aos diplomados pelo mestrado profissional, são conferidas as mesmas prerrogativas e grau idênticos aos dos diplomados no mestrado acadêmico, inclusive, no que se refere ao exercício da docência (VILLELA; BATISTA, 2016).

Para Munari et al. (2014, p. 205), o que mais diferencia o mestrado profissional do acadêmico é a necessidade da elaboração de um produto que venha agregar à pesquisa realizada as atividades profissionais, que possibilite "a formação de profissionais externos à academia que saibam desenvolver e utilizar a pesquisa para agregar valor às suas atividades profissionais, tendo uma análise crítica da prática do trabalho".

Nesse sentido, o mestrado profissional (MP) contribui com os serviços, levando propostas que auxiliam na resolução de problemas enfrentados no seu cotidiano. Segundo a Portaria $\mathrm{n}^{\circ} 7$ de 22 de junho de 2009 (BRASIL, 2009b) em seu artigo IX, inciso 3, os produtos decorrentes das pesquisas realizadas no Mestrado Profissional poderão ser apresentados como: projetos técnicos; desenvolvimento de aplicativos, materiais didáticos e instrucionais; processos e técnicas; produção de programas de mídia; composições; concertos; protocolo experimental ou de aplicação em serviço; proposta de intervenção em procedimentos clínicos ou de serviço pertinente; projeto de aplicação ou produção de instrumentos, equipamentos e 
projetos de inovação tecnológica dentre outros, de acordo com a natureza da área e a finalidade do curso (BRASIL, 2009b).

Em virtude do exposto, pode-se perceber que o MP requer, do aluno, as habilidades e competências exigidas de um aluno do mestrado acadêmico, indo além, ao lhe ser solicitado o desenvolvimento de um material como os listados acima. Isso pode ser entendido como uma importante ferramenta na integração e complementação entre os problemas provenientes do campo social e profissional e o conhecimento gerado na universidade (VILLELA; BATISTA, 2016; LEITE et al., 2017).

Latini et al., (2011, p. 47), declaram que a proposta do MP, "propicia a redução do distanciamento social presente até então na relação entre o sujeito que pesquisa e os que constituem seu objeto de estudo". Os autores deste artigo consideram ainda, que em termos de produção de conhecimento, as pesquisas realizadas no MP têm como característica o fato de serem desenvolvidas a partir de uma perspectiva "de dentro" do contexto analisado. Dessa maneira o MP busca efetuar uma mudança qualitativa na formação dos profissionais que já estão inseridos no mundo do trabalho, conservando o mesmo padrão de exigência e de qualidade do mestrado acadêmico.

\section{METODOLOGIA}

\section{A PROPOSTA METOdológica QUE FAVORECEU A ELABORAÇÃo dos PRODUTOS}

Diante dos problemas relacionados ao tabagismo, a necessidade de se investir na formação e na mudança das práticas dos profissionais das unidades de saúde foi que o estudo escolheu a abordagem qualitativa e como referencial teórico-metodológico a Análise Institucional (AI) que teve sua origem nos anos 60 na França, mas, cujos antecedentes vêm desde os anos 40. No Brasil surgiu nos anos 70, quando o país ainda vivia sob o regime da ditadura militar. Introduziu-se junto a alguns departamentos e grupos de pesquisa de universidades brasileiras e de outras organizações, congregando os mais diferentes tipos de profissionais (L'ABATTE et al., 2013).

A AI utiliza-se de um método constituído de um conjunto articulado de conceitos, como instituído, instituinte, institucionalização, implicação, analisador, encomenda e demanda que visa compreender uma realidade social a partir das falas dos sujeitos atravessados pelas instituições (L’ABATTE, 2017).

Utilizou-se a AI na modalidade socioclínica institucional, proposta por Gilles Monceau em 1998, como uma nova maneira de compreender a realidade por meio de 
intervenções em grupo, trabalhando com a dinâmica institucional em análises localizadas, em um determinado estabelecimento (MONCEAU, 2015).

A socioclínica institucional se desenvolve por meio de oito características e destas, no estudo realizado foram contempladas: a análise da encomenda e das demandas; a participação dos sujeitos nos dispositivos; a análise das transformações à medida que o trabalho avança; a aplicação da modalidade de restituição; a análise das implicações do pesquisador e dos participantes; a produção de conhecimentos; a atenção aos contextos e as interferências institucionais (MONCEAU, 2013). É importante salientar que estas características não se constituem em passos com ordem pré-estabelecida. No entanto, seja qualquer que seja a ordem eleita, todos os passos devem ocorrer durante o processo de intervenção (MONCEAU, 2015).

“A pesquisa intervenção na Análise Institucional é aplicada quando circunscrita à realidade dos grupos, onde o método de intervenção consiste em criar um dispositivo de análise social coletiva. Consiste em analisar coletivamente uma situação coletiva" (LOURAU, 1993, p. 13-14). Deve-se lembrar que um dos objetivos da intervenção é produzir um processo de autoanálise de todos os participantes (MONCEAU, 2013).

E, foi com esta proposição, que se organizaram encontros com profissionais de saúde para debaterem no coletivo, questões referentes ao tabagismo abordadas durante a formação destes; quais os principais problemas que percebiam em relação à cessação de fumar; que atividades de promoção e prevenção poderiam ser propostas em relação ao controle do tabagismo na ESF.

Os encontros aconteceram em 2018 e 2019, após aprovação pelo Comitê de Ética da Universidade Federal Fluminense com o Parecer n ${ }^{\circ}$ 2.930.317. O cenário foi em um Módulo Médico de Família, de Niterói/RJ constituído por três equipes, formadas de três Médicos Generalistas, dois Enfermeiros, três Técnicas de Enfermagem, cinco Agentes Comunitários de Saúde (ACS) e uma equipe de saúde bucal com uma Cirurgiã Dentista e uma Auxiliar de Saúde Bucal. Para ampliar a oferta de saúde contou-se com o Núcleo de Apoio à Saúde da Família (NASF) que tem ainda, com Fisioterapeuta, Fonoaudiólogo e Terapeuta Ocupacional. A unidade recebe alunos de Enfermagem, Farmácia e Medicina da Universidade Federal Fluminense, atende a 1786 famílias, totalizando 5317 indivíduos cadastrados (FUNDAÇÃO MUNICIPAL DE SAÚDE DE NITERÓI, 2017).

Foram convidados a participar da pesquisa todos os profissionais da unidade. Compareceram ao primeiro encontro 15 profissionais, e no segundo, 18, dentre eles: ACS, enfermeiros, médicos e técnicos de Enfermagem. Durante os encontros, os debates foram acontecendo de maneira espontânea, possibilitando que fossem identificadas as características 
da socioclínica institucional, e, situações que favoreceram pensar em estratégias que deram origem aos produtos.

Para a coleta dos dados, além dos encontros, foi ainda utilizado um diário da pesquisadora e as anotações das atas das reuniões do grupo de tabagismo. O diário para Lourau (1993, p. 51) seria a narrativa do pesquisador em seu contexto histórico-social, um pesquisador implicado com e na pesquisa. Trata-se de uma técnica capaz de restituir, na linguagem escrita, o trabalho de campo, possibilitando "produzir um conhecimento sobre a temporalidade da pesquisa", e aproximando o leitor da cotidianidade do que foi possível produzir num dado contexto, evitando interpretações "ilusórias", "fantasiosas" da produção científica. Com relação às anotações da pesquisadora nas atas dos grupos de tabagismo, estas foram importantes por registrar sentimentos e desafios dos tabagistas na cessação de fumar, e a participação dos alunos de Farmácia e da docente nestes grupos, que se constituíram por meio das observações da pesquisadora em participantes do estudo.

Pode-se dizer que o referencial teórico-metodológico proposto constituiu-se em um indutor de mudanças nas práticas dos profissionais de saúde e dos acadêmicos da Universidade Federal Fluminense, pois ao colocar em debates as diversas facetas do tabagismo, mobilizou o grupo a pensar em estratégias que aproximassem os profissionais de saúde dos problemas abordados no coletivo. Estas reflexões, como referiram Latini et al., (2011), Munari et al., (2014) e Villela e Batista (2016), motivaram os profissionais a cogitar estratégias que integrassem entre os problemas percebidos no cotidiano dos profissionais de saúde e o conhecimento gerado nos centros formadores, contribuindo também, para diminuir o distanciamento social entre o pesquisador e seu objeto de estudo. Este pensar favoreceu a elaboração de um instrumento intitulado "Formulário de identificação de tabagistas e da vulnerabilidade familiar: um olhar para crianças e adolescentes", que depois de validado tornou-se o produto do estudo. Decorrente dos movimentos provocados naquele contexto pelo processo de intervenção, os alunos de Farmácia, docente, pesquisadora e enfermeira pensaram em uma nova estratégia de formação e elaboraram um curso voltado ao Agentes Comunitários de Saúde denominado “Abordagem intensiva do fumante para cessação do tabagismo: curso de capacitação:", o que constituiu mais uma produção naquele cenário.

\section{RESULTADOS}

DESENVOLVIMENTO DO "FORMULÁRIO DE IDENTIFICAÇÃO DE TABAGISTAS E DA VULNERABILIDADE FAMILIAR: UM OLHAR PARA CRIANÇAS E ADOLESCENTES" 
Como abordado anteriormente, o produto resultou dos debates, por ocasião do primeiro encontro nos moldes da intervenção socioclínica institucional, quando se abordava a percepção dos profissionais sobre o tabagismo. Um aspecto bastante enfocado foi sobre quem eram os tabagistas, moradores de uma comunidade de pescadores localizada no município de Niteró́/RJ e, sobretudo, como as crianças e adolescentes que convivem com os fumantes podem ser influenciados no uso do tabaco. Os depoimentos levaram a pensar o quanto esta população é vulnerável, sendo necessário que os profissionais de saúde estejam atentos às dinâmicas familiares e pensem em estratégias de promoção e prevenção voltadas a estas famílias. Vejamos o que referem aos participantes no diálogo abaixo:

Mas eu pensava assim [...] que eu achava que tinha acabado essa coisa de criança comprar cigarro. Mas não acabou ainda não. Até um tempo atrás eu vi um pai pedir a uma criança de sete a oito anos para comprar cigarro para ele. Os comerciantes ainda vendem [...]. (UAI) Mas não é proibido vender cigarro para crianças? (AA)

Mas vendem né [...] vendem porque a criança diz que é para o pai, a mãe, a tia. (EII) É mesmo. Eu tenho uma tia que fuma, aí uma vez ela pediu: você vai a rua pega cigarro para mim. Eu comprei um Country e aí eu vi uma imagem tão feia cheguei aí eu falei: Dinda você tem certeza de que você vai continuar fumando? Aí ela falou vira, vira, vira por que eu nem olho isso. Aí ela colocou do lado contrário. (EII)

Minha avó também pedia para eu e minha irmã comprarmos cigarros para ela até aos sábados e domingos as seis horas da manhã!!!! Ai eu ficava pedindo a Jesus: faz a minha vó parar de fumar [...]. Porque tinha que ir, por que se não levantasse ela batia na gente. (EII)

Eu comecei a fumar muito cedo. Meu pai fuma há 40 anos. Um dia meu pai pediu para acender um cigarro para ele [...]. Foi minha primeira tragada. (IEO)

Perguntei a menininha de seis anos o que ela achava da mamãe dela fumar e ela me responde: eu gosto do cigarro porque tem o cheirinho da mamãe. (IA)

Diante destes relatos, trazendo experiências pessoais e profissionais, os participantes começaram a refletir sobre que ações de promoção e prevenção poderiam ser desenvolvidas pela equipe de saúde, em famílias de fumantes. Entendiam os profissionais, a grande responsabilidade dos serviços de saúde em estarem atentos não apenas aos fumantes, mas, sobretudo, para suas famílias, conhecendo as pessoas que estão expostas ao tabaco. Destacaram também a responsabilidade dos centros formadores em preparar os futuros profissionais a pensarem no tabagismo como um grave problema de saúde pública, que deve ser amplamente debatido na teoria e nos cenários de prática.

Essa problemática levou os participantes a pensarem em um produto que viesse a atender às necessidades de promoção e prevenção do tabagismo junto às famílias, seja incorporando ações nas práticas dos profissionais de saúde, ou na aprendizagem dos 
estudantes favorecendo a formação dos futuros profissionais. A elaboração deste produto foi resultante das seguintes etapas descritas no Quadro 1:

Quadro 01: Atividades desenvolvidas com os participantes para a promoção e prevenção do tabagismo no segundo semestre de 2018

\begin{tabular}{|c|c|c|c|}
\hline Etapas & $\begin{array}{l}\text { Dispositivos/ } \\
\text { Instrumentos }\end{array}$ & Participantes & Ação \\
\hline $\begin{array}{l}\text { Primeira } \\
\text { Etapa }\end{array}$ & $\begin{array}{l}\text { Primeiro encontro } \\
\text { socioclínico } \\
\text { institucional }\end{array}$ & $\begin{array}{l}\text { Pesquisadora, } \\
\text { orientadores, } 15 \\
\text { profissionais de saúde } \\
\text { (ACS, enfermeiros, }\end{array}$ & $\begin{array}{l}\text { Debates coletivos sobre a } \\
\text { problemática } \\
\text { tabagismo }\end{array}$ \\
\hline
\end{tabular}

médicos, técnicos de

enfermagem)

\begin{tabular}{|c|c|c|c|}
\hline $\begin{array}{l}\text { Segunda etapa } \\
\text { (ver obs. 1) }\end{array}$ & $\begin{array}{l}\text { Grupo de } \\
\text { Tabagistas } \\
\text { Diário da } \\
\text { pesquisadora } \\
\text { Atas das reuniões } \\
\text { dos grupos de } \\
\text { tabagismo }\end{array}$ & $\begin{array}{l}\text { Pesquisadora } \\
7 \text { alunos farmácia } \\
1 \text { docente de } \\
\text { farmácia }\end{array}$ & $\begin{array}{l}\text { Convite aos alunos de } \\
\text { farmácia (que estão na } \\
\text { unidade nos dias dos } \\
\text { grupo de tabagismo) para } \\
\text { participação nas ações de } \\
\text { promoção e prevenção ao } \\
\text { tabagismo. }\end{array}$ \\
\hline $\begin{array}{l}\text { Terceira etapa } \\
\text { (ver obs. } 2 \text { ) }\end{array}$ & $\begin{array}{l}\text { Elaboração de um } \\
\text { formulário para } \\
\text { levantamento de } \\
\text { tabagistas }\end{array}$ & $\begin{array}{l}\text { Pesquisadora } \\
\text { Orientadoras }\end{array}$ & $\begin{array}{l}\text { Planejamento de um } \\
\text { instrumento que viesse } \\
\text { atender as necessidades } \\
\text { apontadas pelo grupo } \\
\text { com relação aos } \\
\text { tabagistas e suas famílias }\end{array}$ \\
\hline Quarta etapa & $\begin{array}{c}\text { Apresentação e testagem } \\
\text { do formulário para } \\
\text { levantamento de } \\
\text { tabagistas }\end{array}$ & $\begin{array}{l}\text { Profissionais da unidade } \\
\text { Pesquisadora }\end{array}$ & $\begin{array}{l}\text { Explicações aos } \\
\text { profissionais de saúde, } \\
\text { sobre a relevância do } \\
\text { formulário para } \\
\text { identificação de } \\
\text { tabagistas e de crianças e } \\
\text { adolescentes expostas ao } \\
\text { fumo }\end{array}$ \\
\hline $\begin{array}{l}\text { Quinta etapa } \\
\text { (ver obs. 3) }\end{array}$ & $\begin{array}{l}\text { Formulário para } \\
\text { levantamento de } \\
\text { tabagistas }\end{array}$ & $\begin{array}{l}\text { Pesquisadora } \\
\text { Profissionais de } \\
\text { saúde, docente, } \\
\text { alunos de farmácia }\end{array}$ & $\begin{array}{l}\text { Convite para aplicar o } \\
\text { formulário nas atividades } \\
\text { de ensino, consultas, pré- } \\
\text { consultas, sala de vacina } \\
\text { sala de espera e de } \\
\text { curativos, visitas } \\
\text { domiciliares e grupos } \\
\text { educativos }\end{array}$ \\
\hline $\begin{array}{l}\text { Sexta etapa } \\
\text { (ver obs. } 4 \text { ) }\end{array}$ & $\begin{array}{l}\text { Segundo encontro } \\
\text { socioclínico institucional } \\
\text { (Restituição) }\end{array}$ & $\begin{array}{l}\text { Pesquisadora } \\
18 \text { Profissionais de saúde } \\
\text { ( ACS, enfermeiros, } \\
\text { médicos, técnicos de } \\
\text { enfermagem) } \\
\text { Orientadores }\end{array}$ & $\begin{array}{l}\text { Análise e apresentação } \\
\text { dos dados coletados no } \\
\text { formulário. } \\
\text { Sugestões de } \\
\text { modificações no } \\
\text { formulário. } \\
\text { Debates sobre a pouca } \\
\text { adesão na aplicação do } \\
\text { formulário. }\end{array}$ \\
\hline
\end{tabular}

Fonte: Elaborado pelas autoras (2019) 
Obs. 1 - Salientamos que na segunda etapa, o trabalho de preceptoria com os alunos da Farmácia, realizado pela pesquisadora, buscou favorecer sua formação e foi registrado no diário da pesquisadora e nas atas realizadas no final dos grupos de tabaco, constituindo-se também em material de análise da intervenção;

Obs. 2 - Pretendemos na terceira etapa, elaborar um instrumento que não interferisse no processo de trabalho dos profissionais de saúde, de fácil aplicação, e contemplando a coleta dos dados necessários para se conhecer o número de tabagistas que frequenta a unidade de saúde e de crianças e adolescentes expostos ao tabaco em suas famílias.

Obs. 3 - A quinta etapa constitui-se na testagem do instrumento precedido pela interlocução da pesquisadora junto aos profissionais da unidade para que compreendessem a relevância da aplicação do formulário e conhecessem seus objetivos, a saber: estimar os usuários tabagistas que querem parar de fumar; identificar os usuários tabagistas que moram com crianças e adolescentes; ampliar o número de visitas domiciliares para todo fumante que responder que tem crianças ou adolescentes no domicílio; ampliar a adesão dos tabagistas nos grupos de tabagismo.

Obs. 4 - Destacamos na sexta etapa, as dificuldades decorrentes do número reduzido de profissionais de saúde que aplicaram o formulário, mesmo após ampla negociação com eles para que entendessem o formulário como um instrumento de promoção e prevenção do tabagismo, e não como mais uma tarefa imposta a eles. Estas questões foram colocadas em debates coletivos no encontro de restituição, que na socioclínica institucional trata-se não apenas de uma devolutiva, mas de um elemento metodológico utilizado para apresentar os resultados parciais da pesquisa aos participantes, permitindo que possam se aprofundar ou questionar as análises realizadas (MONCEAU, 2015). A restituição permitiu ampliar a compreensão dos participantes e do pesquisador sobre as dificuldades em realizar mudanças no processo de trabalho dos profissionais de saúde.

De maneira a deixar mais claro o instrumento proposto, o Quadro 2 traz o consolidado de seis formulários aplicados pela Técnica de Enfermagem na sala de préconsulta, da unidade de saúde, no período de 23 a 30 de maio de 2019.

\begin{tabular}{|c|c|c|c|c|c|}
\hline $\mathbf{N}^{o}$ & $\begin{array}{l}\text { PRONTUÁRIO/ } \\
\text { PARTICIPANTES }\end{array}$ & É FUMANTE & $\begin{array}{l}\text { MORA COM CRIANÇAS E/OU } \\
\text { ADOLESCENTE (IDADE) }\end{array}$ & $\begin{array}{l}\text { QUER PARAR DE } \\
\text { FUMAR }\end{array}$ & $\begin{array}{c}\text { ANOTAR O } \\
\text { NOME/WHATSAPP }\end{array}$ \\
\hline 23/05/2019 & 11 & $\begin{array}{l}\text { S- } 07 \\
\text { N-04 }\end{array}$ & $\begin{array}{cc}0 \text { a } 10- & 10 \\
10 \text { a } 15- & 07 \\
15 \text { a } 19- & 04 \\
\text { Sem crianças-0 }\end{array}$ & S -04 & $\begin{array}{c}\text { Todos que } \\
\text { desejavam parar de } \\
\text { fumar deixaram } \\
\text { contato }\end{array}$ \\
\hline $24 / 05 / 2019$ & 9 & S- 06 & 0 a 10- 06 & & \\
\hline ISSN 1983-7011 & & & & & 164 \\
\hline
\end{tabular}


Ensino, Saúde e Ambiente - V13 (2), pp. 155-176, AGO. 2020

\begin{tabular}{|c|c|c|c|c|c|}
\hline & & $\mathrm{N}-03$ & $\begin{array}{c}10 \text { a } 15-03 \\
15 \text { a } 19-03 \\
\text { Sem crianças- } 0\end{array}$ & S-04 & Idem \\
\hline $27 / 05 / 2019$ & 12 & $\begin{array}{l}\text { S- } 07 \\
\text { N-05 }\end{array}$ & $\begin{array}{cc}0 \text { a } 10- & 09 \\
10 \text { a } 15- & 08 \\
15 \text { a } 19- & 06 \\
\text { Sem crianças- } 01\end{array}$ & $S-04$ & Idem \\
\hline $28 / 05 / 2019$ & 15 & $\begin{array}{l}\text { S- } 08 \\
\text { N-07 }\end{array}$ & $\begin{array}{cc}0 \text { a } 10- & 11 \\
10 \text { a } 15- & 09 \\
15 \text { a } 19- & 06 \\
\text { Sem crianças-01 }\end{array}$ & $S-06$ & Idem \\
\hline $29 / 05 / 2019$ & 07 & $\begin{array}{l}\text { S- } 04 \\
\text { N-04 }\end{array}$ & $\begin{array}{cc}0 \text { a } 10- & 07 \\
10 \text { a } 15- & 03 \\
15 \text { a } 19- & 02 \\
\text { Sem crianças- } 0\end{array}$ & $S-02$ & Idem \\
\hline $30 / 05 / 2019$ & 10 & $\begin{array}{l}\text { S- } 08 \\
\text { N-02 }\end{array}$ & $\begin{array}{cc}0 \text { a } 10- & 09 \\
10 \text { a } 15- & 06 \\
15 \text { a } 19- & 03 \\
\text { Sem crianças-0 }\end{array}$ & $S-04$ & Idem \\
\hline Total & $\begin{array}{c}64 \\
\text { responderam } \\
\text { o formulário }\end{array}$ & $\begin{array}{c}40 \\
\text { Referiram } \\
\text { ser } \\
\text { fimantes }\end{array}$ & $\begin{array}{cc}0-10- & 52 \\
10-15- & 36 \\
15-19- & 24 \\
\text { Sem crianças- }(02)\end{array}$ & 24 & $\begin{array}{l}24 \text { pessoas } \\
\text { deixaram o } \\
\text { contato }\end{array}$ \\
\hline
\end{tabular}

Fonte: Elaborado pelas autoras (2019)

Constatamos que o formulário foi de fácil aplicação, e o tempo utilizado pelos profissionais foi de cinco a dez minutos, pouco interferindo nas atividades já programadas. Foi possível verificar também que o número de fumantes em relação ao total de participantes que responderam as perguntas do formulário $(62,5 \%)$ foi bastante representativo, revelando que o fumo ainda é buscado por muitas pessoas, o que reforça a necessidade de se ampliar naquele contexto as ações de promoção e prevenção. Neste primeiro instrumento, não se pensou em fazer uma identificação de homens e mulheres fumantes, mas após a consolidação dos resultados, decidiu-se incluir este item, pois como as mulheres ficam mais tempo junto às crianças e adolescentes podem ter maior influência na iniciação do fumo. O resultado indica o número de fumantes que desejam parar de fumar (60\%) fornece um bom indicativo, de que ações de promoção e prevenção devem ser implantadas e continuadas, como é o caso de grupo de tabagistas já em atividade naquele cenário. Mais preocupante é o número de crianças e adolescentes expostas ao tabaco, 112 no total, que revelam a necessidade de programar visitas domiciliares a estas famílias e de realizar um planejamento para abordagens individualizadas para cada situação encontrada.

No segundo encontro, chamado na Socioclínica Institucional de Restituição, quando os resultados do formulário foram apresentados e colocados em debates no coletivo, optou-se por acrescentar neste rol de questões, mais duas colunas: uma coluna com a identificação de 
sexo e uma última coluna com o item observações. Foi acordado também, que as estratégias seriam voltadas apenas à prevenção do tabagismo com as crianças, dada a maior dificuldade de abordagem com os adolescentes. Em relação ao acolhimento dos tabagistas, este seria realizado por todos os profissionais da unidade. Quanto às visitas domiciliares às famílias que tinham crianças convivendo com tabagistas, deliberou-se que seriam atividades já possíveis de serem implantadas pelos profissionais.

Com relação à pouca adesão dos profissionais na aplicação do formulário, foi apontado durante a reunião que o instrumento, depois de organizado, deverá passar pela avaliação dos profissionais de saúde, de preferência em uma reunião, onde possam entender o seu papel neste novo processo de trabalho, e se percebam coparticipantes na elaboração e implementação deste novo material.

Constata-se que durante a operacionalização destas estratégias, que mudanças começaram a ser observadas nas práticas dos profissionais de saúde e também da docente de Farmácia, que acompanhava a implantação das novas atividades, o que a estimulou a ampliar as ações de promoção e prevenção ao tabagismo com os estudantes, possibilitando a elaboração do segundo produto do estudo.

\section{DESENVOLVIMENTO DA “ABORDAGEM INTENSIVA DO FUMANTE PARA CESSAÇÃO DO TABAGISMO: CURSO DE CAPACITAÇÃO”}

Desde o primeiro encontro de intervenção, foi possível constatar movimentos de mudanças no contexto das práticas de cuidado e de ensino em saúde, seja com relação às atividades desenvolvidas pelos profissionais ou pela docente de Farmácia e seus alunos.

Durante o primeiro encontro, outro aspecto abordado referia-se à formação dos participantes e se tinham tido contato durante a formação com medidas de promoção e prevenção ao tabagismo. Ao considerar que os participantes tinham profissões diversificadas, esperou-se nos depoimentos, que a temática tivesse sido abordada no processo formativo por algum deles. Porém, referiram pouco ou nenhum contato com o tema como relatado a seguir:

No meu tempo em que eu estudei me formei não tinha nada sobre tabagismo, não se falava em tabagismo. Falavam muito em doença DST, mas minha época não tinha, não. Não sei agora se tem $[\ldots] .(I E E)$

Não tive nenhum contato com ações de combate ao tabagismo durante a formação. Só tive uma formação sobre o tabagismo porque depois eu fui fazer um curso dentro do INCA [...]. E aprender com o INCA. É, mas no decorrer da minha vida profissional, enquanto médica, não era coisa que se desse importância a prevenção. Se dava muita importância a coisa curativa, mas enquanto prevenção não era essa bola toda. (IIA)

Na minha formação não teve. (UIAA) 
Na minha época não aprendi nada sobre tabagismo, mas a minha filha, estudando com 11 anos na escola dela já tem, faz grupos, chama os pais para falar sobre o problema do fumo. Hoje na escola dela, pelo menos fala sim. (IEO)

Não me lembro de ter nenhum evento, ou aula que abordasse falasse sobre o tabagismo. (IA)

Diante destes depoimentos, a docente de Farmácia, que acompanhava os movimentos que os debates provocavam no cotidiano da unidade, propôs à pesquisadora uma maneira mais efetiva de inserir os alunos na promoção e prevenção do tabagismo durante sua formação. Este agir decorria também das constantes queixas dos tabagistas sobre a maneira como os estudantes eram inseridos nos grupos de tabagismo. A docente distribuía os alunos em pares nas atividades de grupo, e a cada encontro, uma nova dupla participava da reunião, o que levava os tabagistas do grupo a solicitar a presença dos alunos anteriores com quem haviam compartilhado suas vivências. Segundo eles, a troca constante de alunos impedia que se formasse o vínculo entre os participantes e destes com os alunos, dificultando que falassem de seus medos e incertezas.

Estas queixas levaram a docente e pesquisadora a pensar em maneiras que viessem minimizar este problema e um novo processo de ensino aprendizado foi pensado. Neste, os alunos de Farmácia (em número de sete) iniciaram juntamente com os fumantes um grupo, onde todos pudessem participar do início até o final das atividades propostas.

De maneira a ampliar o conhecimento dos alunos nos problemas relacionados ao tabaco, a docente e a pesquisadora sugeriram a leitura do caderno da Atenção Básica 40: "Estratégias para o cuidado da pessoa com doença crônica: o cuidado da pessoa tabagista". Após a leitura deste documento, os alunos participaram do grupo de maneira mais ativa, o que aumentou a confiabilidade dos tabagistas nos estudantes.

Este movimento na unidade incentivou que outros profissionais se inserissem neste processo formativo, e a enfermeira juntamente com a docente e a pesquisadora pensaram na possibilidade do desenvolvimento de um curso de capacitação para os Agentes Comunitários de Saúde, sobre o tabagismo, desenvolvidos pelos alunos do segundo período de Farmácia, como descrito no Quadro 3:

Quadro 3. Curso de capacitação para Agentes Comunitários de Saúde: abordagem intensiva do fumante para cessação do tabagismo.

\begin{tabular}{|c|c|c|c|c|}
\hline Período & $\begin{array}{c}\text { Temas abordado/Carga } \\
\text { Horária }(\mathbf{C H}) \text { teórica }\end{array}$ & Metodologia & $\begin{array}{c}\text { Carga horária } \\
\text { (CH) prática }\end{array}$ & Avaliação \\
\hline $\begin{array}{c}\text { Última } \\
\text { semana } \\
\text { abril }\end{array}$ & $\begin{array}{c}\text { Tema: Entendendo as } \\
\text { razões de fumar. } \\
2019\end{array}$ & $\begin{array}{c}\text { Aula expositiva } \\
\text { Como o fumo afeta a saúde. } \\
\text { CH-2h }\end{array}$ & $\begin{array}{c}\text { Entrevistas com fumantes a } \\
\text { Debates } \\
\text { partir do questionamento: } \\
\text { em sua opinião o fumo } \\
\text { afeta a saúde? } \\
\text { CH-2h }\end{array}$ & $\begin{array}{c}\text { Avaliação oral do } \\
\text { conteúdo teórico }\end{array}$ \\
& & & & \\
\hline
\end{tabular}


Ensino, Saúde e Ambiente - V13 (2), pp. 155-176, AGO. 2020

\begin{tabular}{|c|c|c|c|c|}
\hline $\begin{array}{l}\text { Primeira } \\
\text { semana } \\
\text { Maio } \\
2019\end{array}$ & $\begin{array}{c}\text { Tema: Aspectos do } \\
\text { tabagismo. } \\
\text { Dependência química, } \\
\text { psicológica, associação de } \\
\text { comportamento } \\
\text { CH-2h }\end{array}$ & $\begin{array}{l}\text { Debates a partir } \\
\text { de estudos de } \\
\text { caso }\end{array}$ & $\begin{array}{c}\text { Rodas de conversa com } \\
\text { fumantes na sala de espera } \\
\text { sobre a dependência ao } \\
\text { tabaco. } \\
\text { CH-2h }\end{array}$ & $\begin{array}{c}\text { Jogo dos sete erros } \\
\text { sobre a temática } \\
\text { abordada }\end{array}$ \\
\hline $\begin{array}{c}\text { Segunda } \\
\text { semana } \\
\text { maio } \\
2019\end{array}$ & $\begin{array}{c}\text { Tema: Ambivalência } \\
\text { Parar x continuar fumando. } \\
\text { CH-2h }\end{array}$ & $\begin{array}{c}\text { Compartilhando } \\
\text { experiências } \\
\text { Debates em } \\
\text { grupo }\end{array}$ & $\begin{array}{c}\text { Diálogos com fumantes: as } \\
\text { dificuldades da cessação de } \\
\text { fumar } \\
\text { CH-2h }\end{array}$ & $\begin{array}{l}\text { Sugestões sobre a } \\
\text { parte teórica e } \\
\text { prática }\end{array}$ \\
\hline $\begin{array}{l}\text { Terceira } \\
\text { semana } \\
\text { maio } \\
2019\end{array}$ & $\begin{array}{c}\text { Tema: Tratamento } \\
\text { medicamentoso e } \\
\text { intervenção pessoal } \\
\mathrm{CH}-2 \mathrm{~h}\end{array}$ & $\begin{array}{c}\text { Aula expositiva } \\
\text { e dialogada }\end{array}$ & $\begin{array}{c}\text { Conhecendo os } \\
\text { medicamentos na prática. } \\
\text { Observação de consulta } \\
\text { médica ao tabagista } \\
\text { CH-2h } \\
\end{array}$ & $\begin{array}{l}\text { Avaliação escrita } \\
\text { do conteúdo } \\
\text { teórico } \\
\text { (10 questões } \\
\text { objetivas) } \\
\end{array}$ \\
\hline $\begin{array}{l}\text { Quarta } \\
\text { semana } \\
\text { maio } \\
2019\end{array}$ & $\begin{array}{c}\text { Tema: Tabagismo ativo e } \\
\text { passivo. } \\
\text { CH-1h30min }\end{array}$ & $\begin{array}{l}\text { Debates a partir } \\
\text { de estudos de } \\
\text { caso }\end{array}$ & $\begin{array}{c}\text { Entrevista com famílias de } \\
\text { fumantes a partir do } \\
\text { questionamento: em sua } \\
\text { opinião o que é um } \\
\text { fumante passivo? } \\
\text { CH-2h }\end{array}$ & $\begin{array}{l}\text { Avaliação geral } \\
\text { escrita do curso, } \\
\text { pontuando as } \\
\text { dificuldades, } \\
\text { potencialidades }\end{array}$ \\
\hline
\end{tabular}

Fonte: Elaborado pelas autoras (2019)

Importante destacar que a parte prática foi desenvolvida semanalmente em atividades de dispersão. No início de cada aula, abria-se espaço para que fizessem a restituição das atividades práticas abordando as dificuldades, aspectos positivos e percepções pessoais.

Esta capacitação veio ao encontro da necessidade de fortalecer o processo de trabalho dos ACS, na abordagem e identificação de tabagistas possibilitando que tivessem um novo olhar sobre o agravo, e como ele podia estar afetando as famílias dos fumantes.

Os ACS consideraram importante trocar informações sobre o tabagismo, seus riscos e consequências para a saúde e, após o treinamento, perceberam-se com mais segurança nas intervenções no território.

Os alunos que participaram de todos os grupos avaliaram ter adquirido um grande aprendizado, despertando neles um novo olhar para as dificuldades dos fumantes em deixar de fumar, devido à dependência química provocada pela nicotina. Relataram que tanto a experiência nos grupos quanto à elaboração de um curso para os ACS e sua aplicação, foram muito importantes para sua formação como profissionais de saúde.

Ao pensar em dar sequimento a este projeto, que se constituiu em mais um produto do estudo, foi proposto à continuidade do mesmo a cada semestre, entendendo ser necessário ampliar a participação de outros profissionais e de outros estudantes da área da saúde em atividades educativas, voltadas ao controle do tabagismo.

Para caracterizar a atividade como um curso de capacitação, foi elaborado um certificado aos alunos de Farmácia como ministrantes, em reconhecimento aos esforços na produção e disseminação dos conhecimentos relacionados ao tabagismo e, aos ACS, foi 
conferido um certificado como participantes, de maneira a incentivá-los a participar de outros cursos.

\section{DISCUSSÃO: ALGUMAS CONSIDERAÇÕES TEÓRICAS SOBRE OS PRODUTOS APRESENTADOS}

Como já abordado em diversas partes deste artigo, o referencial teóricometodológico da Análise Institucional nos moldes da socioclínica institucional, foi fundamental para os resultados do estudo e elaboração dos produtos. Torna-se, portanto necessário conhecer onde as características da socioclínica institucional foram evidenciadas.

As características "análise da encomenda e das demandas" foram evidenciadas quando o pesquisador colocou sua encomenda aos participantes para debaterem o problema do tabagismo e os participantes colocam suas demandas para as instituições ensino, com relação à falta de abordagem desta problemática na formação, e também, para a instituição serviços, para que desenvolvam ações mais efetivas na promoção e prevenção do tabagismo.

A característica "participação dos sujeitos no processo de intervenção" foi contemplada durante os debates nos primeiro e segundo encontros, quando todos os participantes falaram livremente o que pensavam sobre a temática (MONCEAU, 2013; 2015).

As características "análise das implicações pessoais, afetivas e profissionais" com o tabagismo e as "interferências das instituições" família, educação, saúde, religião que envolvem o ato de fumar ou de cessação do fumo, representam os elementos que constantemente atravessam as rotinas e que constituem as ações, de forma que analisá-los possibilita identificá-los (MONCEAU, 2013; 2015). Reconhecer tais atravessamentos no coletivo se faz importante para o trabalho da intervenção socioclínica institucional (MOURÃO; SOASSUME, 2015; ROSSI; PASSOS, 2014).

Barbier (1985) reconheceu três tipos de implicações: a de natureza psicoafetiva (afetivas), a histórico existencial (ideológicas), estrutural profissional (profissionais). No caso deste estudo, as implicações do pesquisador com o tabagismo ficaram evidentes nas anotações do diário do pesquisador e nas atas das reuniões dos tabagistas, na maneira como propôs mudanças naquele contexto com relação às ações de promoção e prevenção do tabagismo. Suas implicações ideológicas deixaram transparecer a crença de que sempre se pode melhorar a qualidade da assistência no Sistema Único de Saúde, revelando como as instituições ensino, saúde e família atravessam suas condutas pessoais e como profissional de saúde. As implicações afetivas e profissionais dos participantes se fizeram presentes nos relatos sobre as vivências pessoais e profissionais relacionadas ao tabagismo, revelando que muitas 
instituições atravessavam os debates durante os encontros. E, esta capacidade de reconhecer e analisar as implicações é que favoreceram as mudanças e a busca de estratégias.

A característica "análise das transformações, que ocorreram à medida que o trabalho avança" pode ser percebida nas mudanças de posicionamentos dos participantes durante os encontros, principalmente ao redefinirem seu papel como cidadãos e como profissionais de um sistema público de saúde, colocando-se como corresponsáveis pelo programa de tabagismo, que não pode ficar sob a responsabilidade de um pequeno grupo de profissionais, mas de todos profissionais de saúde, de estudantes e docentes daquela unidade de saúde (MONCEAU, 2013; 2015).

A característica "aplicação da modalidade de restituição" foi fundamental para se colocar para o coletivo o que foi discutido na reunião anterior e abrir espaços para se apresentar em debates os entraves com relação ao formulário, as diferentes percepções dos participantes com relação ao seu papel no programa de tabagismo, a necessária integração teoria e prática aproximando a academia dos serviços (MONCEAU, 2013; 2015).

A característica "intenção de produzir conhecimentos" foi evidenciada nas mudanças propostas para a formação dos alunos de Farmácia; nas práticas dos profissionais de saúde, e na oportunidade de se ampliar o conhecimento de todos os participantes sobre o tabagismo sua promoção e prevenção sejam nos debates ou no curso de capacitação (MONCEAU, 2013; 2015).

Com relação à elaboração dos produtos, corrobora-se com o pensamento de Bagatini e Schorr (2019, p. 130) ao afirmar que cada produto "sendo único em suas características, necessita de um planejamento e desenvolvimento próprios", fato que aconteceu com a elaboração destes dois produtos, que mesmo acontecendo quase simultaneamente em um mesmo contexto, mobilizaram diferentes atores, em diferentes atividades.

Quanto à validação dos produtos aqui apresentados, Ruiz et al., (2014, p. 20) e Leite (2018, p. 335) fornecem uma proposta a partir de cinco aspectos: atração; compreensão; envolvimento; aceitação e mudança, para que os produtos educativos possam ser validados.

Com relação à "atração" pode-se dizer que as perguntas sugeridas pelos autores foram contempladas na elaboração e implementação dos produtos a saber: o que chama mais a atenção neste material? O que mudaria para melhorar o que não gostou? Estas perguntas foram feitas durante a elaboração do produto e no encontro de restituição favorecendo as modificações.

No quesito "compreensão" que está relacionado ao aprendizado dos conteúdos do material pelo grupo destinatário, pode-se dizer que pela simplicidade do primeiro produto e pelas estratégias pedagógicas do segundo produto, ele foi contemplado. 
Com relação ao aspecto "envolvimento", pode-se dizer que o primeiro produto foi parcialmente contemplado, pois ao se colocar o questionamento: o destinatário reconhece o material como destinado a ele? Muitos profissionais não aderiram à aplicação do formulário, fato que deverá ser mais bem trabalhado naquele contexto.

No aspecto "aceitação", onde se aborda nos questionamentos se o material é ofensivo em sua linguagem ou imagens e se favorece o preconceito com relação ao seu enfoque, podemos dizer que não foram evidenciados estes aspectos.

$\mathrm{O}$ aspecto que se refere a "mudanças" busca atender aos seguintes questionamentos: O material estimula uma mudança de olhar e de atitude? O material pede que faça algo? Você está disposto a realizar? Recomendaria este material? Pelo acompanhamento da aplicação dos produtos, pode-se afirmar que eles foram capazes de induzir mudanças. Porém, entende-se que os produtos são processos em construção, as mudanças precisam ser entendidas em seu aspecto de movimentos e não de terminalidade.

Com relação às práticas dos profissionais, segundo o Programa de Tabagismo do Ministério da Saúde, os profissionais, sempre que possível, devem promover ações de informação, incentivo e apoio ao abandono do tabagismo. Pesquisas confirmam que as abordagens rápidas, repetidas em cada consulta, reforçando os malefícios do tabaco e a importância da cessação do seu uso, aumentam significativamente as taxas de abstinência. $\mathrm{O}$ impacto em termos de saúde pública parece ser superior com abordagens breves em um maior número de usuários em relação às abordagens intensivas direcionadas a poucos usuários (BRASIL, 2015). Complementam Berk, Rocha e Gatto (2016) que estratégias como práticas educativas no ensino da saúde tendo como objetivo a prevenção das doenças, são favorecidas por uma frequência e uma periodicidade contínua, recomendando a expansão destas estratégias para diferentes espaços.

Quanto ao curso de capacitação, destacam Soares et al., (2017) que nas práticas educativas em saúde, torna-se necessário que além dos discursos, os sentidos sejam mobilizados para que se possa melhor entender as dificuldades dos tabagistas na mudança de hábitos, necessários à cessação de fumar. Para os autores, a educação em saúde constitui-se em um dispositivo capaz de favorecer o diálogo e o conhecimento, associada ao conceito ampliado de saúde. Nessa concepção, o educador é considerado um mediador do processo de elaboração do conhecimento e o educando um participante ativo deste processo, participando conjuntamente da produção de conhecimento.

Esta maneira de entender a educação se fundamenta na concepção problematizadora e libertadora de educação desenvolvida por Paulo Freire, que concebe o educando como um ser histórico e social, consciente de sua potência transformadora no mundo (FREIRE, 2011). 
Complementam Menezes e Avelino (2016), que o importante é criar espaços para a escuta das necessidades das pessoas e para a sua informação. Se a prática educativa acontece em grupos, se permite que todos possam falar sobre seus problemas e buscar soluções, conjuntamente com os profissionais, de forma que a informação circule da experiência técnica à vivência prática de cada indivíduo, então se pode dizer que está no caminho certo.

Com relação à formação dos profissionais de saúde, destaca-se que ainda existe muito distanciamento entre o que preconizam os programas de tabagismo, e as diretrizes curriculares dos profissionais de saúde, com o que efetivamente acontece na prática dos profissionais de saúde e dos alunos em formação com relação às ações de promoção e prevenção do tabagismo, revelando as contradições nas instituições saúde e ensino.

Esta constatação traz o referencial teórico-metodológico da Análise Institucional, ao assinalar que são as contradições que aparecem nos campos de intervenção, que possibilitam que transformações sejam buscadas naquele espaço. Durante o processo de intervenção, à medida que os participantes colocam suas demandas em relação ao problema que está em debate, pode-se perceber atitudes e depoimentos ambivalentes, ou seja, que revelam as contradições que compõem as implicações pessoais, afetivas, familiares, profissionais e ideológicas dos participantes com relação ao tabagismo (GUILLIER, 2003; MONCEAU, 2015).

Com base nestas contradições, é que os produtos foram pensados e elaborados, nas brechas daquele espaço instituído, criando condições para que outras maneiras de realizar a prática junto aos tabagistas e suas famílias fossem construídas pelos profissionais de saúde e estudantes em formação, revelando-se em movimentos instituintes naquele contexto (BAREMBLITT, 2012).

\section{CONSIDERAÇÕES FINAIS}

Pode-se dizer quanto aos produtos e, especificamente, ao primeiro produto, que como todo instrumento que é introduzido em um estabelecimento, ele provoca as instituições ali presentes, como as instituições de saúde e ensino, a repensarem suas práticas, o que não se faz sem conflitos. Por constituir-se em uma prática instituinte em um espaço já instituído pelas práticas cotidianas, sua operacionalização e implantação não se processa sem resistências.

Diante disso, deve-se pensar coletivamente em estratégias de implantação, esperando que os resultados de sua aplicabilidade, revelem seu alcance na prevenção do tabagismo, abrindo espaço para que estes movimentos instituintes, sejam assimilados nas práticas dos profissionais de saúde, docentes e alunos de graduação. 
A utilização deste referencial teórico-metodológico, ainda que se constitua em um indutor de mudanças nas práticas do ensino e dos serviços, tem como contraponto, ser ainda pouco utilizado pelos pesquisadores e/ou profissionais de saúde, necessitando que este conhecimento seja amplamente difundido em eventos e publicações para o conhecimento e debates.

Com relação ao alcance dos produtos pode-se dizer que mesmo sendo construídos para uma realidade específica, ambos têm um formato fácil de ser replicado em outras unidades de saúde, desde que haja interesse dos centros formadores e dos serviços, no sentido de entender que as práticas já instituídas contra o tabagismo, não atendem mais às necessidades de um controle eficaz dos tabagistas e de suas famílias.

\section{REFERÊNCIAS}

BAGATINI, L.; SCHORR, C. M. Metodologias ativas no ensino profissionalizante: uma experiência na disciplina de pesquisa e desenvolvimento de produtos. Ensino, Saúde e Ambiente, v. 12, n. 1, p. 123-142, 2019. Disponível em:

http://periodicos.uff.br/ensinosaudeambiente/article/view/21531/16621. Acesso em: 12 jun. 2019.

BARBIER, R. Pesquisa-ação na instituição educativa. Rio de Janeiro: Zahar, 1985.

BAREMBLITT, G. Compêndio de Análise Institucional. 5. ed. Belo Horizonte: Instituto Felix Guattari, 2012.

BERK, A.; ROCHA, M.; GATTO, T. O potencial do espaço coletivo para a divulgação de informações preventivas de promoção da saúde: uma prática educativa sobre HPV e câncer do colo do útero. Ensino, Saúde e Ambiente, v. 9, n. 3, p. 189-206, 2016. Disponível em: http://periodicos.uff.br/ensinosaudeambiente_backup/article/view/14737. Acesso em: $10 \mathrm{dez}$ 2018.

BRASIL, Ministério da Saúde. Secretaria de Atenção à Saúde. Departamento de Atenção Básica. Estratégias para o cuidado da pessoa com doença crônica: o cuidado da pessoa tabagista. Brasília: Ministério da Saúde, 2015. Disponível em:

http://bvsms.saude.gov.br/bvs/publicacoes/estrategias_cuidado_pessoa_doenca_cronica_cab3 5.pdf. Acesso em: 15 nov. 2017.

BRASIL. Ministério da Educação. Fundação Coordenação de Aperfeiçoamento de Pessoal de Nível Superior-CAPES. Portaria normativa . $^{\circ} 17$ de 28 de dezembro de 2009. Dispõe sobre o mestrado profissional no âmbito da Fundação Coordenação de Aperfeiçoamento de Pessoal de Nível Superior - CAPES. Brasília: Ministério da Educação, 2009a. Disponível em: https://www.capes.gov.br/images/stories/download/legislacao/PortariaNormativa_17MP.pdf Acesso em: 14 jul. 2018.

BRASIL. Ministério da Educação. Fundação Coordenação de Aperfeiçoamento de Pessoal de Nível Superior - CAPES. Portaria n 7 de 22 de junho de 2009. Dispõe sobre o mestrado profissional no âmbito da Fundação Coordenação de Aperfeiçoamento de Pessoal de Nível Superior - CAPES. Brasília: Ministério da Educação, 2009b. Disponível em: 
https://www.capes.gov.br/images/stories/download/legislacao/Revogada-Portaria-Normativan_7-22-de-junho-2009-Mestrado-Profissional.pdf

BRASIL. Ministério da Educação. Portaria Capes $n^{\circ}$ 080, de 16 de dezembro de 1998. Dispõe sobre o reconhecimento dos mestrados profissionais e dá outras providências. Brasília: Ministério da Educação, 1998. Disponível em:

https://www.capes.gov.br/images/stories/download/legislacao/Portaria_CAPES_080_1998.pdf . Acesso em: 15 ago 2018.

BRASIL. Ministério da Saúde. Instituto Nacional de Câncer. Organização Pan-Americana da Saúde. Agência Nacional de Vigilância Sanitária. Iniciativa Bloomberg para Reduzir o Uso de Tabaco. Aliança de Controle do Tabagismo. Rio de Janeiro: INCA, 2007. Disponível em: http://www1.inca.gov.br/inca/Arquivos/t_Tabagismo.pdf. Acesso em: 12 maio 2017.

BRASIL. Ministério da Saúde. Instituto Nacional do Câncer. Abordagem e Tratamento do Fumante- consenso 2001. Rio de Janeiro: INCA, 2001. Disponível em: http://portal.saude.sp.gov.br/resources/ses/perfil/profissional-dasaude/homepage//tratamento_fumo_consenso.pdf. Acesso em: 15 nov. 2018.

BRASIL. Ministério da Saúde. Portaria n. 687 de 30 de março de 2006. Aprova a Política Nacional de Promoção da Saúde. Brasília: Ministério da Saúde, 2006. Disponível em: http://www.saude.mt.gov.br/upload/documento/154/portaria-n-687-de-30-de-marco-de-2006aprova-a-politica-de-promocao-da-saude-[154-261011-SES-MT].pdf. Acesso em: 12 nov. 2018.

BRASIL. Ministério da Saúde. Portaria no 571/GM/MS, de 05 de abril de 2013. Brasília: Ministério da Saúde, 2013. Disponível em: http://bvsms.saude.gov.br/bvs/saudelegis/gm/2017/MatrizesConsolidacao/comum/2335.html. Acesso em: 15 mar. 2019.

FREIRE, P. Pedagogia da autonomia: saberes necessários à prática educativa. São Paulo: Paz e Terra, v. 1. p. 40-41, 2011.

FUNDAÇÃO MUNICIPAL DE SAÚDE DE NITERÓI. Unidade Saúde da Família Mario Munhoz Monroe. Niterói : FMSN, 2017.

GUILLIER, D. L'analyse des implications dans les pratiques socianalytiques : celles de l'analyste ou/et celles de son client ?. L'Homme et la Société, v. 1, n. 147, p. 35-53, 2003. Disponível em: www.cairn.info/revue-1-homme-et-la-societe-2003-1-page-35.htm. Acesso em: 15 jun. 2019.

L'ABBATE, S. Analyse Institutionnelle et Santé Collective au Brésil: effets d'une articulation théorique. In: MONCEAU G. (ed.). Enquêter ou intervenir? Effets des recherches sociocliniques. Nîmes: Champ Social, p. 129-37, 2017.

L'ABBATE, S.; MOURÃO, L. C.; PEZZATO, L. M. Análise Institucional e Saúde Coletiva. São Paulo: Hucitec, 2013

LATINI, R. M. et al. Análise dos produtos de um mestrado profissional da área de ensino de ciências e matemática. Ensino, Saúde e Ambiente, v. 4, n. 2, p. 45-57, 2011. Disponível em: http://ensinosaudeambiente.uff.br/index.php/ensinosaudeambiente/article/viewFile/94/9. Acesso em: 11 jul. 2018. 
LEITE, I. C. M. et al. Ser aluno de um mestrado profissional. Revista de Enfermagem UFPE On line, v. 11, n. 12, p. 5102-5109, 2017. Disponível em: https://doi.org/10.5205/1981-8963v11i12a25060p5102-5109-2017. Acesso em: 15 jun. 2019.

LEITE, P. S. C. Produtos Educacionais em Mestrados Profissionais na Área de Ensino: uma proposta de avaliação coletiva de materiais educativos. Atas CIAIQ, v. 1, 2018. Disponível em: https://www.proceedings.ciaiq.org/index.php/ciaiq2018/article/view/1656. Acesso em: 21 jul. 2018.

LOURAU, R. L. Análise Institucional e prática de pesquisa Análise Institucional e práticas de pesquisa. In: RODRIGUES, H. B. C. (org.) René Lourau na UERJ. Rio de Janeiro: UERJ, 1993.

MENEZES, K. K. P.; AVELINO, P. R. Grupos operativos na Atenção Primária à Saúde como prática de discussão e educação: uma revisão. Cadernos de Saúde Coletiva, v. 24, n. 1, p. 124130, 2016. Disponível em: http://www.scielo.br/pdf/cadsc/v24n1/1414-462X-cadsc-24-1124.pdf. Acesso em: 15 jun. 2019.

MONCEAU, G. A socioclínica institucional para pesquisas em educação e em saúde. In: L’ÁBBATE, S.; MOURÃO, L. C.; PEZZATO, L. M. (org.). Análise Institucional e Saúde Coletiva no Brasil. São Paulo: Hucitec, 2013.

MONCEAU, G. Técnicas socioclínicas para a Análise Institucional das práticas sociais. Psicologia em Revista, v. 21, n. 1, p. 197-217, 2015. Disponível em: http://periodicos.pucminas.br/index.php/psicologiaemrevista/article/view/8752/8861. Acesso em: 16 set. 2017.

MOURÃO, L. C.; SOASSUME, T. Reflexões sobre as ações do Programa Hiperdia em centros de saúde: implicações profissionais. Diversitates, v. 7, n. 2, p. 34-43, 2015. Disponível em: http://www. diversitates.uff.br/index.php/1diversitates-uff1/ article/view/103. Acesso em: 19 set. 2018.

MUNARI, D. B. et al. Professional Master's degree in Nursing: knowledge production and challenges. Revista Latino-Americana de Enfermagem, v. 22, n. 2, p. 204-212, 2014.

Disponível em: http://www.scielo.br/scielo.php?pid=S010411692014000200204\&script=sci_arttext\&tlng=es. Acesso em: 13 jun. 2019.

ROMERO, L. C.; COSTA E SILVA, V. L. 23 Anos de controle do tabaco no Brasil: a atualidade do Programa Nacional de Combate ao Fumo de 1988. Revista Brasileira de Cancerologia, v. 57, n. 3, p. 305-314, 2011.

ROSSI, A.; PASSOS, E. Análise Institucional: revisão conceitual e nuances da pesquisaintervenção no Brasil. Revista EPOS, v. 5, n. 1, p. 156-181, 2014. Disponível em: http://pepsic.bvsalud.org/scielo.php?pid=S2178700X2014000100009\&script=sci_abstract\&tlng=en. Acesso em: 11 jun. 2019.

RUIZ, L. et al. Producción de materiales de comunicación y educación popular. Buenos Aires: Departamento de Publicaciones de la Facultad de Derecho y Ciencias Sociales de la Universidad de Buenos Aires, 2014. Disponível em:

https://studylib.es/doc/4516210/producci\%C3\%B3n-de-materiales-de-comunicaci\%C3\%B3ny-educaci\%C3\%B3n-popular. Acesso em: 29 jun. 2019. 
SOARES, A. N. et al. Dispositivo educação em saúde: reflexões sobre práticas educativas na atenção primária e formação em enfermagem. Texto \& Contexto Enfermagem, v. 26, n. 3, 2017. Disponível em: http://dx.doi.org/10.1590/0104-07072017000260016. Acesso em: 19 jun. 2018.

VILLELA, R. B.; BATISTA, N. A. Mestrados Profissionais de Ensino em Ciências da Saúde no Brasil: concepções e práticas. In: $5^{\circ}$ Congresso Ibero Americano de Investigação Qualitativa. Anais... Porto: CIAIQ, p. 173-182, 2016. Disponível em: http://proceedings.ciaiq.org/index.php/ciaiq2016/article/view/601/590. Acesso em: 18 jul. 2017.

\section{SOBRE OS AUTORES}

\section{AUTOR 1.}

Mestre em Ensino na Saúde Formação Interdisciplinar para o SUS. Médica com Especialização em Saúde Pública e: Saúde da Família desde 2001. Atua como Médica de Família em Niterói-RJ desde 2011.

Elaboração do artigo.

\section{AUTOR 2.}

Doutorado em Enfermagem pela UFRJ/RJ, atuou como enfermeira na Secretaria de Estado de São Paulo na área de planejamento e gestão; na UNIGRANRIO como docente e coordenadora do curso de Enfermagem da UNIGRANRIO, e no desenvolvimento de projetos de extensão universitária voltados à saúde da família, do idoso; do escolar e adolescente com foco na promoção da saúde e na interdisciplinaridade. Participa do projeto de pesquisa "Práticas profissionais e formação em saúde no SUS: contribuições e inovações da Análise Institucional para a Saúde Coletiva na UNICAMP/SP. Atualmente é professora colaboradora voluntária do Mestrado Profissional de Ensino na Saúde da Universidade Federal Fluminense (UFF), na linha de pesquisa formação em saúde.

Orientação sobre a escrita do artigo. Revisão geral do manuscrito.

\section{AUTOR 3.}

Pós-doutorado no laboratório École, Mutations et Apprentissage (EMA), da Université de Cergy-Paris, França (2014), doutorado em Saúde Coletiva pela Universidade Estadual de Campinas (2006). Líder do Grupo de Estudos e Pesquisa Análise Institucional e Formação em Saúde - UFF/CNPq. Atualmente é professora associada no Instituto de Saúde Coletiva, atuando em disciplinas do Curso de Graduação em Medicina e no Programa de Mestrado Profissional no Ensino em Saúde, da Universidade Federal Fluminense (UFF). Tem experiência na área de Saúde Coletiva com ênfase no: planejamento e gestão em saúde, enfermagem, educação em saúde, formação em saúde e análise institucional e saúde coletiva, tanto no ensino quanto na pesquisa, como na extensão universitária.

Orientação sobre a proposta metodológica e revisão do artigo 